\title{
Histopathology finds in 431 corneas from transplant receptors in Rio de Janeiro
}

\author{
Achados histopatológicos em 431 córneas \\ de receptores de transplantes no Rio de Janeiro
}

Luiz Carlos Aguiar Vaz'

\begin{abstract}
Four hundred and thirty one cornea from transplant receptors in Rio de Janeiro were analised, most of them received from Banco de Olhos, associated to Brazilian Society of Ophtalmology (SBO) and from Rio-transplante, after temporary closing of Banco de Olhos. There is a markable difference between the percentual and incidence from the most important causes founded in this work, all of them prooved by histopathology, and the causes reported in bibliography at Sorocaba, Porto Alegre, Florianópolis, Manaus and Recife, based only in clinical archives.
\end{abstract}

Keywords: Cornea/pathology; Corneal transplantation/estatistics \& numerical data; Corneal transplantation/epidemiology

\section{Resumo}

Foram examinadas 431 córneas de receptores de transplantes no Rio de Janeiro recebidas em sua maioria do Banco de Olhos associado à Sociedade Brasileira de Oftalmologia (SBO) e, as últimas, do Rio-transplante, após o fechamento temporário do Banco de Olhos. É notável a diferença entre os percentuais e o ordenamento das principais causas de transplante achadas neste levantamento, todos por comprovação histopatológica dos diagnósticos, e as citadas em bibliografia encontradas em Sorocaba, Porto Alegre, Florianópolis, Manaus e Recife baseadas apenas no levantamento dos prontuários clínicos.

Descritores: Córnea/patologia; Transplante de córnea/estatística \& dados numéricos; Transplante de córnea/epidemiologia

\footnotetext{
${ }^{1}$ Department of Pathology, Faculty of Medical Sciences (FCM), Rio de Janeiro State University (UERJ)

Study conducted at the Department of Pathology and Laboratories of the Faculty of Medical Sciences, Rio de Janeiro State UniversityStudyfunded by FAPERJ (Project No. APQ1 E-26/110.414/2007) Programme: Rio Transplante
}

The authors declare no conflict of interest.

Received for publication 12/2/2013 - Accepted for publication 26/2/2014 


\section{INTRODUCTION}

I n 1995, the Eye Bank of the Brazilian Society of Ophthalmology was created for receiving and distributing corneas for transplantation. In 2007, the State Transplant Centre of the State Health Office (CNCDO-RJ/SES) took over management of the Eye Bank nearly a year after it had suspended its activities, as determined by the Brazilian Health Surveillance Agency.

The indication and sorting of recipients is based on the clinical diagnoses of corneal diseases. Histopathological examination of excised corneas can be used to assess diagnostic accuracy and is the basis for statistical aetiological studies, which are interesting both for ophthalmologists and public health services.

This work is the result of a partnership between the Eye Bank and the State University of Rio de Janeiro (UERJ) and its aim was to verify whether transplants in the State of Rio de Janeiro had been correctly indicated. Bullous keratopathy (45\%), infectious keratitis (20\%), keratoconus (12.5\%), graft failure (11\%) and dystrophies $(8 \%)$ were the main reasons for transplantation as identified through histopathological examination.

\section{Methods}

As there was no protocol for submitting corneas to histopathological examination, several surgical specimens were received with incomplete requests which lacked patient identification, a clinical summary on the indication for transplantation, and even the requesting physician's signature. Corneas were divided into halves to undergo processing and paraffin embedding, microtomy between 3 and $5 \mu \mathrm{m}$ and routine haematoxylin-eosin (HE) staining. When necessary, other sections were stained with PAS and Grocott silver to identify fungi, Masson's trichrome, PAS, Congo red, Alcian-Blue for corneal dystrophies, and Von Kossa to identify calcium deposits. It was then determined whether the histopathological findings ${ }^{1}$ were consistent or compatible (when the lack of clinical information in the requests impaired the correlation of findings) with the clinical diagnosis.

\section{Results}

The causes for corneal transplantation were grouped according to the nature of lesions and their frequency (Figure 1), as there is no proposal for classification in the literature. Among

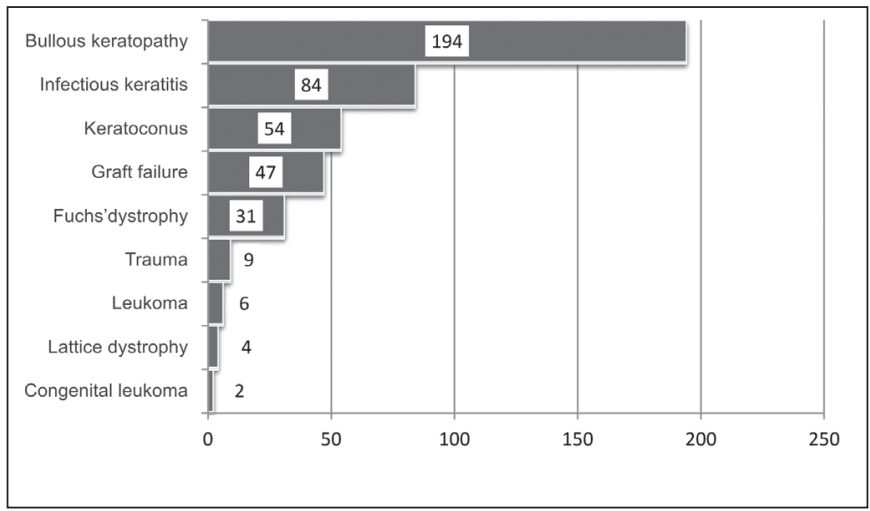

Figure 1: Causes for transplantation - Histopathological diagnosis

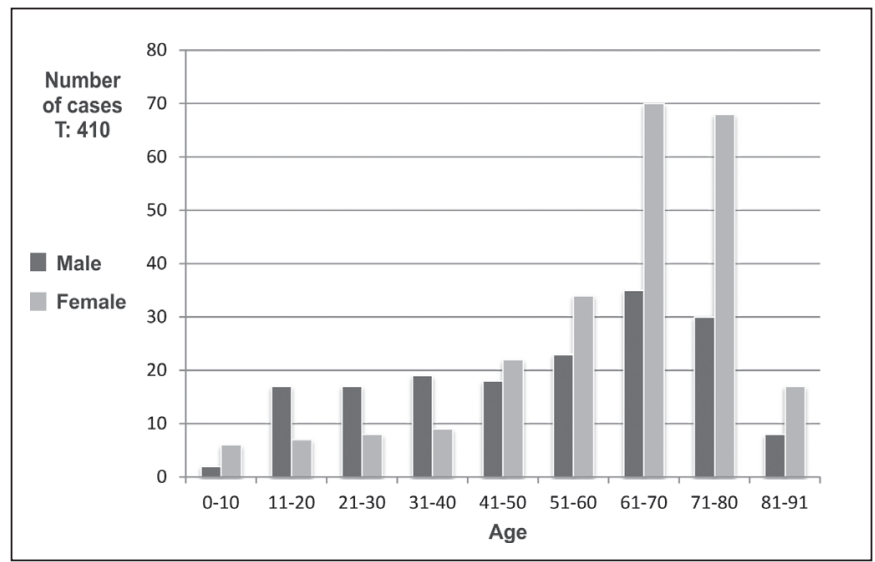

Figure 2: Corneas by gender and age

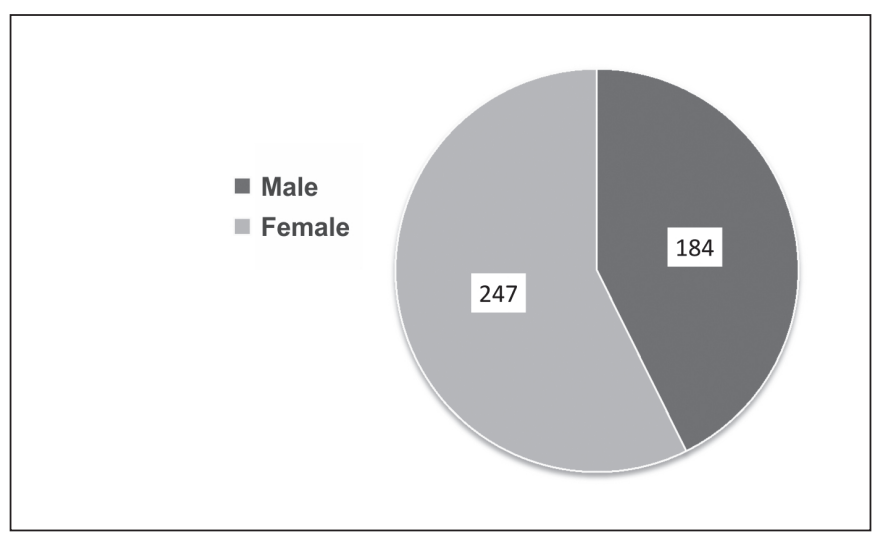

Figure 3: Corneas by gender

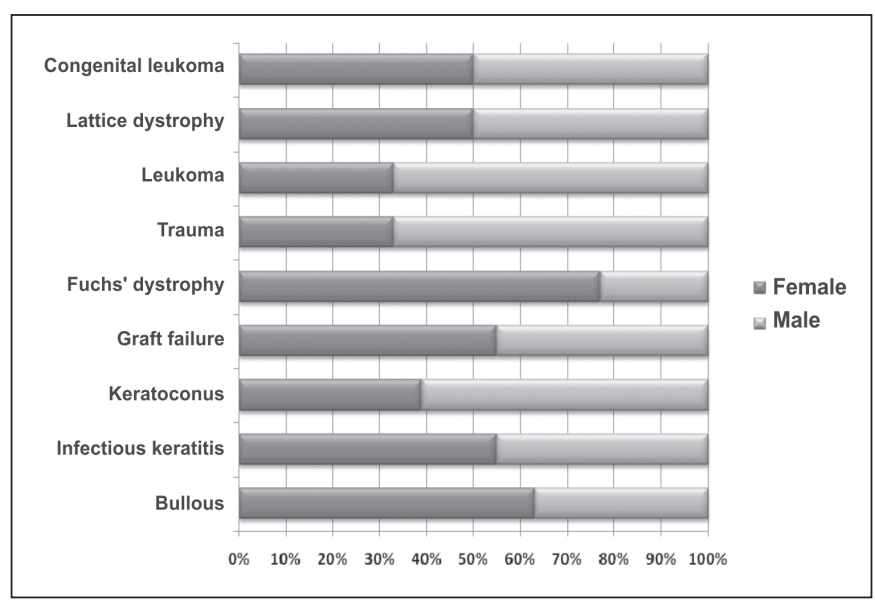

Figure 4: Causes for transplantation - Gender distribution

the nine listed diagnoses, the most frequent was bullous keratopathy (BK), which in all cases resulted from postoperative complications of cataract surgery. Most patients were aged 50-80 years (Figure 2). Cases in which the patient's age was not reported were excluded, which reduced sample size from 431 to 410 .

The number of cases of BK associated with cataract surgery raised the average patient age to 57.5 years and nullified the significance of any differences between genders or age groups (Figure 3) which could exist due to diseases such as keratoconus and Fuchs' dystrophy (Figure 4). 


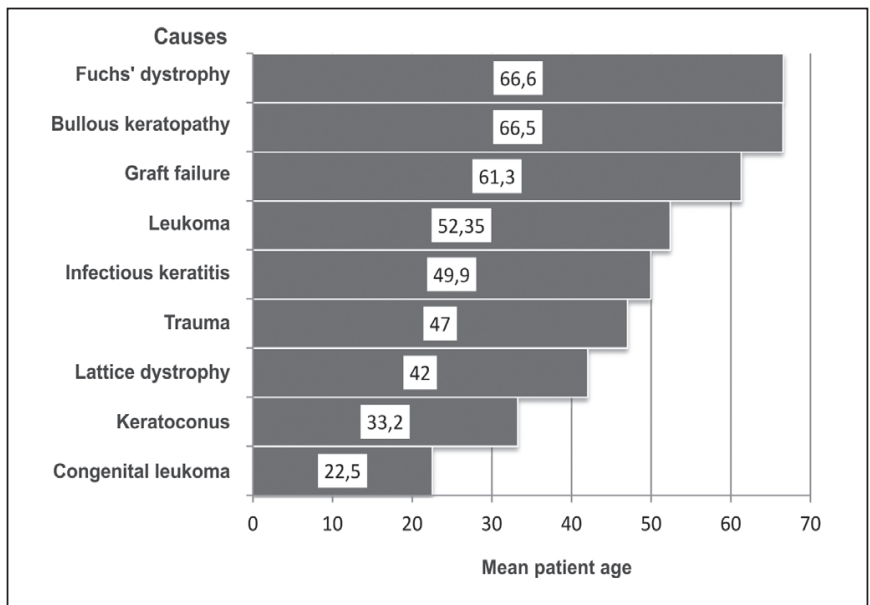

Figure 5: Mean patient age

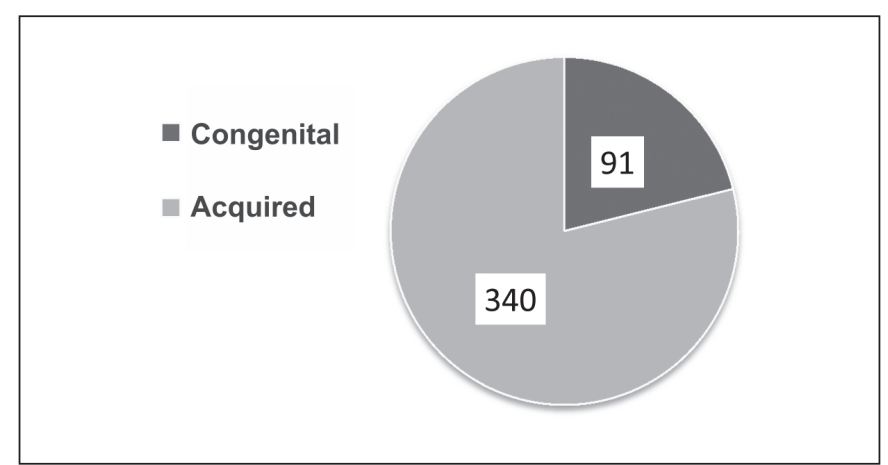

Figure 6: Causes for transplantation

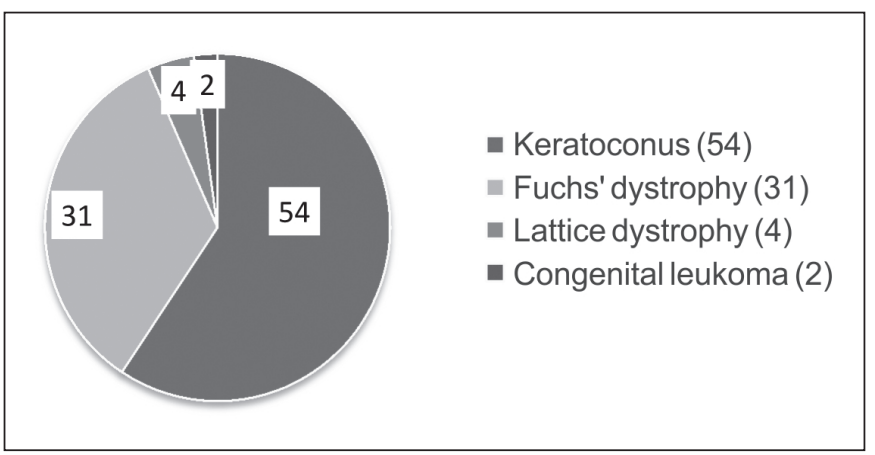

Figure 7: Congenital causes

The comparison of histopathological diagnoses with mean patient age (Figure 5) found expected results: primary causes for corneal disease such as congenital leukomas and keratoconus occurred at younger ages; traumatic injuries and infectious keratitis mainly affected adults of working age; and in cases of graft failure (due to mixed causes) mean patient age was similar to the sample as a whole.

Causes were also divided into congenital or acquired and their frequency was calculated (Figures 6,7 and 8) and plotted on charts to help visualise details for groups with larger sample sizes (Figures 9, 10 e 11).

The curves for infectious keratitis (Figure 9) and keratoconus (Figure 10) were normally distributed and followed the expected trend, with keratoconus starting at school age when patients first complain of visual disturbances.

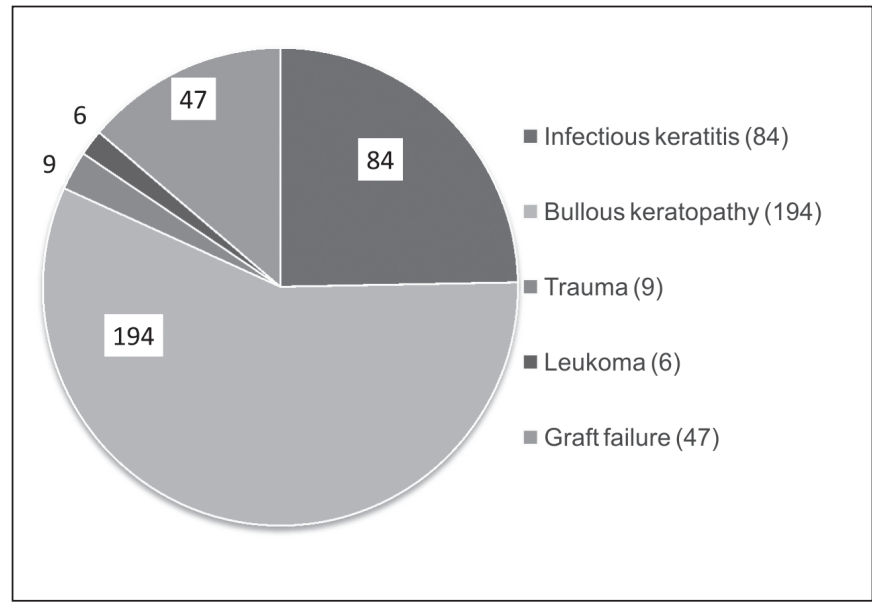

Figura 8: Acquired causes

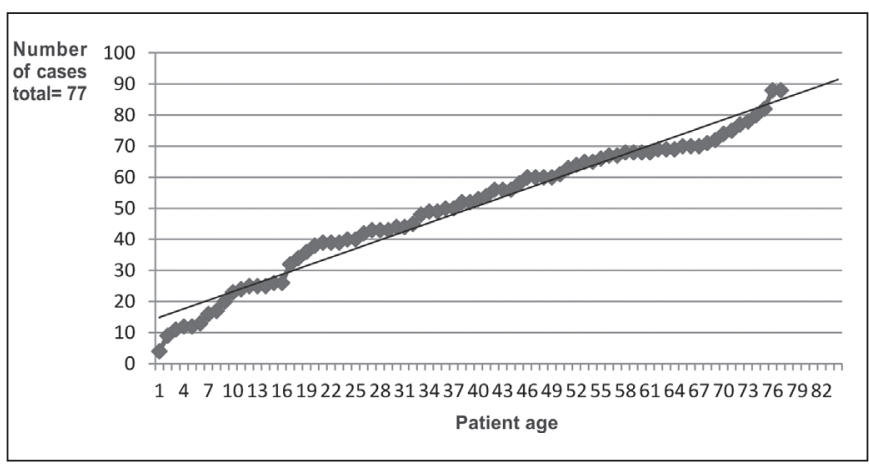

Figure 9: Infectious keratitis - Age distribution

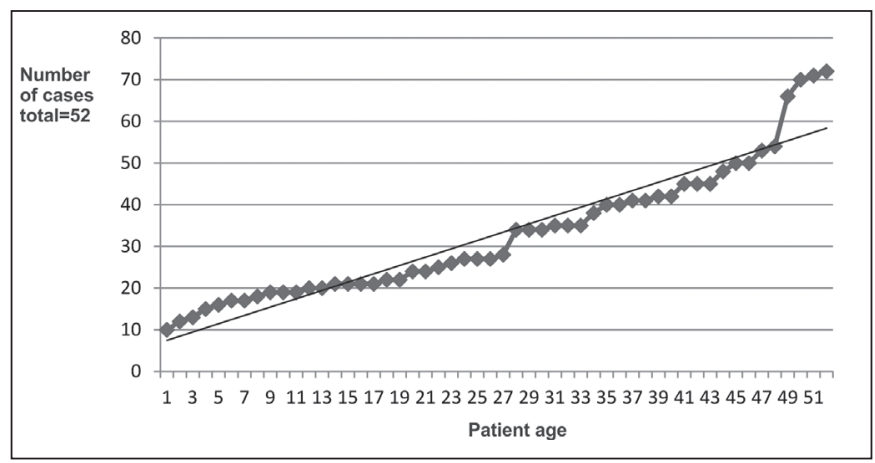

Figure 10: Keratoconus - Age distribution

The charts for Fuchs' dystrophy and Lattice dystrophy (Figure 11) were clearly distinguishable by the number of cases and age extremes. They also differed in terms of prevalence between genders: Figure 4 shows how Fuchs' dystrophy affected mostly women, while Lattice dystrophy was uniformly distributed throughout both genders. The group of congenital or primary causes for transplantation comprised both dystrophies plus the two cases of congenital leukoma (one Peters anomaly and one sclerocornea) and the keratoconus group (Figures 6 and 7).

In the chart for BK by age (Figure 12), the rare cases associated with congenital glaucoma appear distinctly isolated from the others, which are linked to cataract surgery. For the latter, the large number of cases in patients aged 50-90 years produce a continuous line in the scatter plot. 


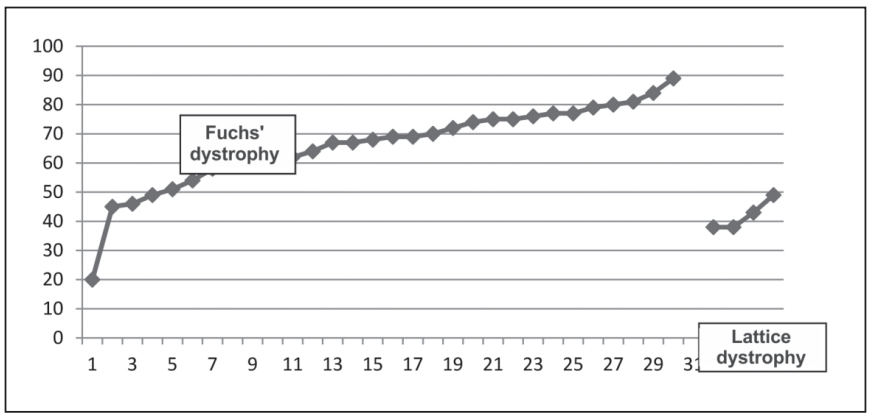

Figure 11: Dystrophies - Age distribution

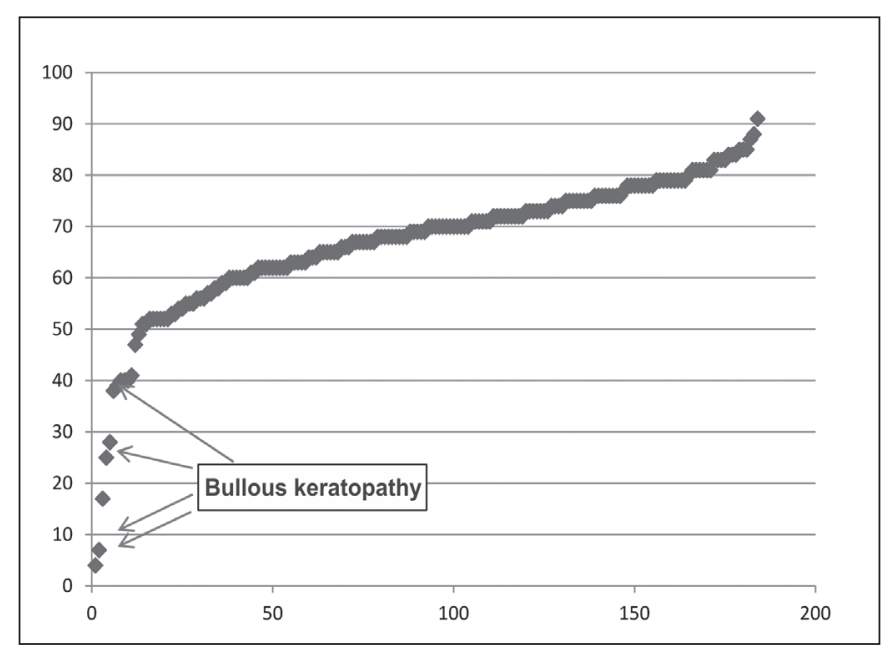

Figure 12: Bullous keratopathy - Age distribution

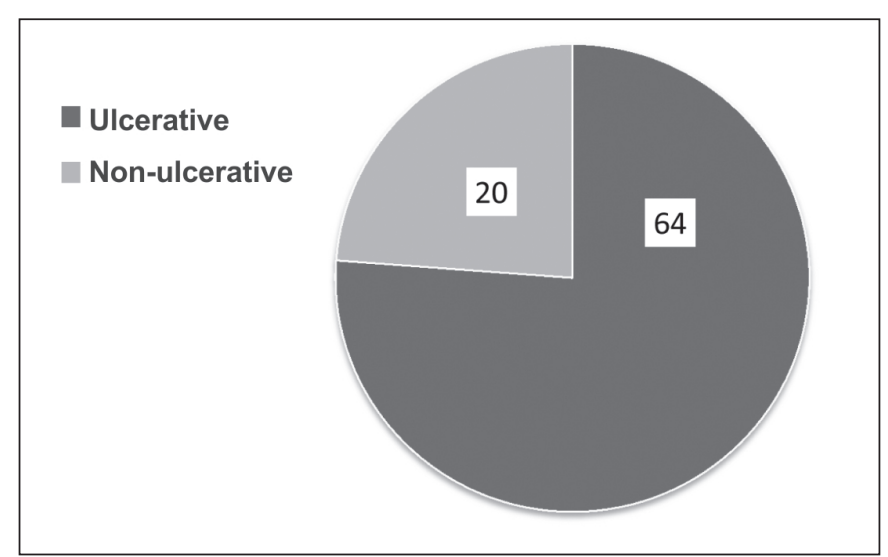

Figure 13: keratitis infectious - number of cases

In the infectious keratitis group (Figure 13), cases were not subdivided by topography as mentioned in literature or in some test orders by surgeons, where they were classified as subepithelial, interstitial, superficial, deep, central or marginal. Any infectious agent, regardless of its nature, can affect any one of these locations depending to the intensity of the infectious process and the length of disease progression. Therefore, we divided cases into ulcerative and non-ulcerative, which is more indicative of the severity of the lesion.

As regards the infectious agents (Figure 14), the aetiology was largely determined based on clinical information, as the

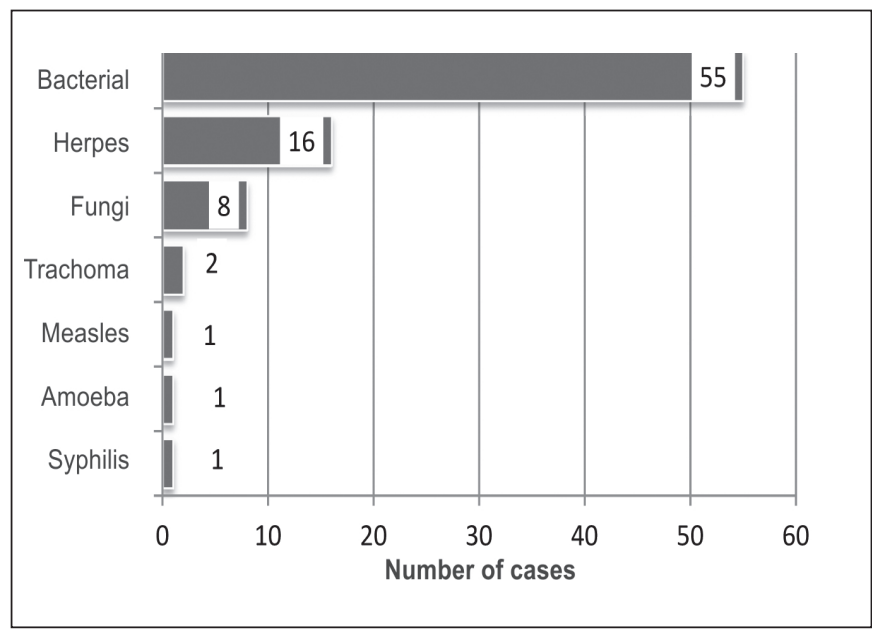

Figure 14: Infectious keratitis - Aetiology

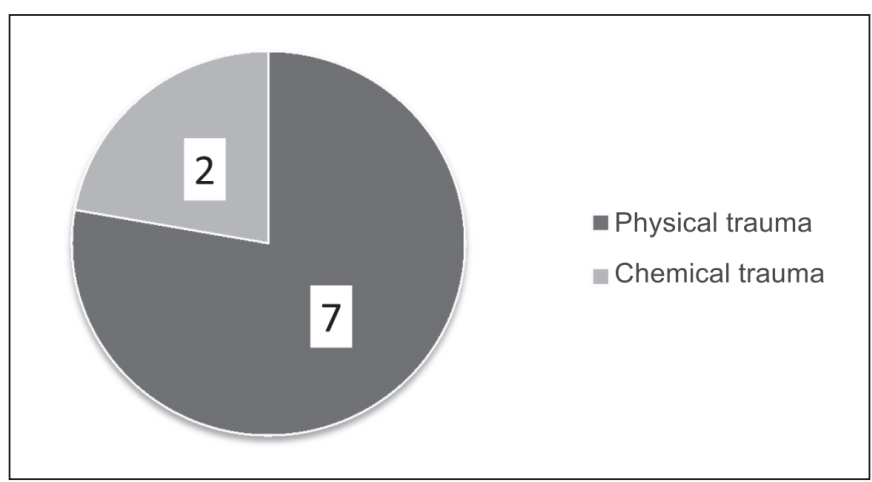

Figure 15: Trauma

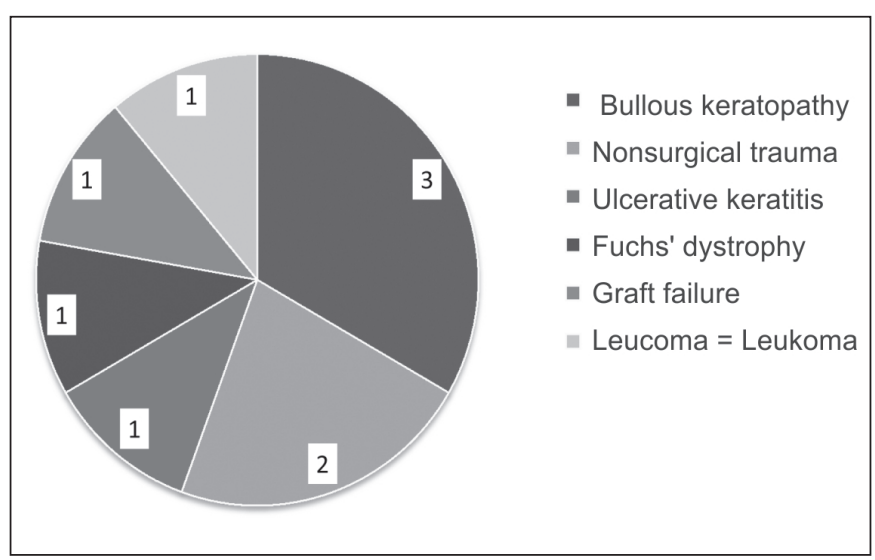

Figure16: Dystrophic calcification

corneas were in the healing phase of the inflammatory process following medical treatment. In principle, bacterial and viral inflammatory processes are considered nonspecific by pathologists, since agent identification depends on culture or antigen verification. Only fungi are visible and identifiable with the aid of special stains such as Grocott silver or PAS. In 3 out of 8 cases, hyphae of Candida sp. were identified.

Although present, the leukoma group (Figures 1, 4, 5 and 8 ) should not exist if clinical information was always available in test orders, which would allow a correlation with histopathology. The term leukoma refers only to a clinically observed corneal 


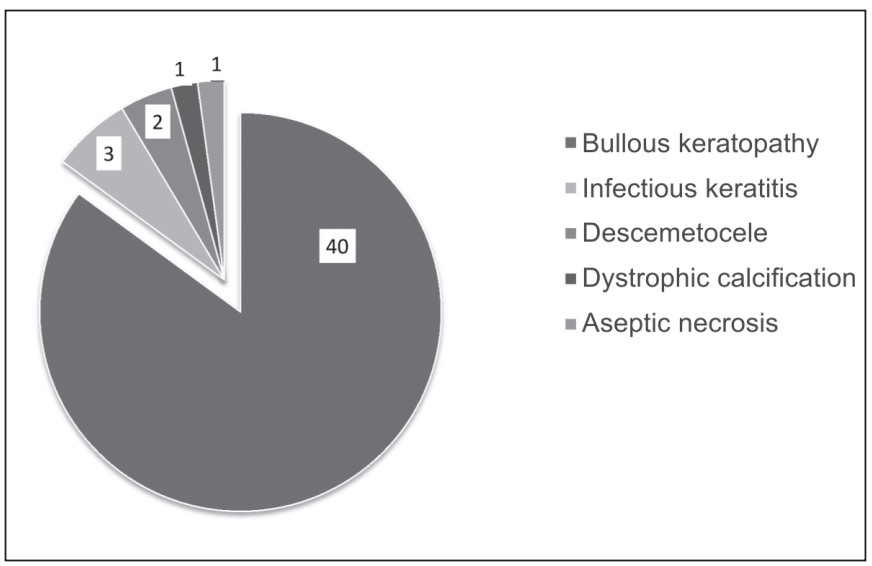

FigurE 17: Graft failure - Main causes

opacity. Histologically, it can range from a mild loss of orientation of keratocytes to an obvious fibrous scar, which can be the final appearance of any corneal disease.

The trauma group (Figure 15) comprised cases of leukoma for which there was a clinical report of nonsurgical trauma. Its small size is surprising considering the large number of work accidents in Brazil. Histological changes ranged from fibrous scarring in older cases to acute inflammatory processes in early injuries with superimposed bacterial infection.

Corneal calcification (Figure 16) did not constitute a separate group of causes for transplantation, but it was suggested in some clinical reports and later confirmed on histopathological examination with Von Kossa staining. The clinical term "calcific band keratopathy" corresponds to the histopathological finding of "metastatic" calcification with uniform deposition of calcium in Bowman's membrane, which is associated with changes in calcium metabolism due to various causes. Irregular deposition of calcium is considered "dystrophic" when it affects previously damaged or dead tissue, which occurred in all cases included in this study.

The graft failure group (Figures 1, 5, 8 and 16) comprised corneas from previous transplants which failed for a number of reasons, but mainly due to BK (Figure 17). Since the total number of transplants performed in the same period is unknown, no conclusions can be drawn on the percentage of failures in this type of surgery.

If 47 corneas were the products of graft failures, there should be an equal number of original corneas from the same patients among the 431 sampled specimens. However, we were only able to match corneas from seven patients. Three of them had had corneas transplanted in both eyes (two due to keratoconus and one to Fuchs' dystrophy) and two had BK.

Figure 18 shows the histological findings in the inflammation and scarring processes for cases of graft failure.

In the keratoconus group (Figures 1, 4, 5, 7 and 10), the higher frequency of male patients (Figure 4) was surprising considering that $70 \%$ of cases reported in literature affect women. The 52 cases were normally distributed in terms of age, with no concentration at any particular age (Figure 10).

\section{Discussion}

Based on histopathological findings, the leading cause for corneal transplantation in the 431 cases included here was BK

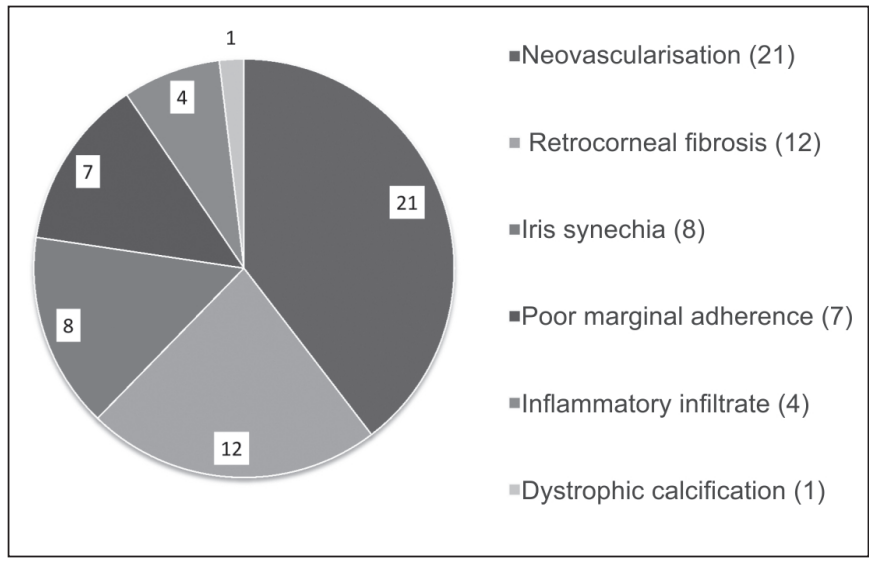

Figure18: Graft failure - Changes associated with bullous keratopathy

following cataract surgery, with keratoconus as the third most frequent diagnosis. These results differed greatly from those of previous studies conducted in cities such as Sorocaba ${ }^{2}$, Campinas $^{3}$, Porto Alegre ${ }^{4}$, Florianópolis ${ }^{5}$, Manaus ${ }^{6}$ and Recife ${ }^{7}$. These studies, however, were based solely on medical records. The percentages would differ even more if graft failures due to BK had also been considered. In view of the varied sources for information, no conclusions can be drawn from the comparison between our histopathological findings and the results from previous studies. However, some speculations can be made on the reasons for this discrepancy.

A clinical study on the epidemiological profile of 320 patients on the waiting list for corneal transplants in the State of Sergipe $^{8}$ also showed a preponderance of BK over keratoconus following cataract extraction, in agreement with studies conducted in the United States and Japan. The simplest explanation would be the increasing elderly population in Rio de Janeiro and in both countries, leading to an increase in the number of cataract procedures. Such explanation, however, is challenged by the demographics of the State of Sergipe as well as the predominance of keratoconus in Europe and in major cities of the State of São Paulo and southern Brazil. Another clinical study on the profile of 35 patients with BK following cataract extraction treated at a public hospital in Rio de Janeiro ${ }^{9}$ found different results depending on the surgical techniques employed, preoperative risk assessment for systemic diseases (such as diabetes mellitus), the evaluation of corneas, and even the experience of professionals involved in the procedures. A iatrogenic factor could then explain the different frequencies found in the leading causes for corneal transplantation and the histopathological findings associated with failed grafts. The frequencies of different causes could therefore not be explained solely by the demographics of different cities, the natural incidence of diseases (favouring keratoconus and producing a normal distribution for infectious keratitis) or incidental causes such as damage from nonsurgical trauma.

One of the objectives of this project was to show that histopathology can be used as a tool for assessing the accuracy of clinical diagnoses which are claimed to justify transplantation. An absolute discrepancy between clinical and histological diagnoses was only found in 4 out of 431 cases, or less than $1 \%$ of the sample. The four cases were referred by the same physician who reported ulceration and descemetocele, both of which are surgical emergencies. The conflicting histopathological diagnoses 
showed two cases of keratoconus and two uncomplicated bullous keratopathies, diseases that require surgery but that are not an emergency. For the remaining cases, histopathology was either completely consistent or compatible (when histopathological findings were nonspecific) with the clinical diagnosis.

Standardising request forms for histopathological examination, which should be merged with corneal transplantation request forms, would prevent the issue of missing clinical information and patient identification due to incomplete requests. An even more effective alternative would be an electronic form that could not be submitted unless all mandatory fields had been filled.

\section{Acknowledgments}

Funded by FAPERJ (Project No.:APQ1 E-26/110.414/2007) Programme: Rio Transplante Rio de Janeiro/RJ, Brazil.

\section{ReferenCes}

1. Myron Yanoff, Ben S. Ocular pathology. 5th ed. Mosby Inc: USA; 2002.

2. Machado Filho O, Machado GA, Macêdo CL, Luz CAB, Cunha M. Indicações de ceratoplastia penetrante em 1993 - Escola Paulista de Medicina. Arq Bras Oftalmol. 1994;57(4):236.

3. Flores VG, Dias HL, Castro RS. [Penetrating keratoplasty indications in "Hospital das Clínicas-UNICAMP"]. Arq Bras Oftalmol. 2007;70(3):505-8. Portuguese.

4. Cattani S, Kwitko S, Kroeff MA, Marinho D, Rymer S, Bocaccio FL. [Indications for corneal graft surgery at the Hospital de Clínicas of Porto Alegre]. Arq Bras Oftalmol. 2002;65(1):95-8. Portuguese.
5. Florence M, Regis-Pacheco LF. [Changing indications for penetrating keratoplasty 1990 -1997]. Arq Bras Oftalmol. 1999;62(3):272-7. Portuguese.

6. Carvalho RC, Moss M, Garrido C, Cohen J, Chaves C. [Indications of corneal transplantation in the State of Amazon, Brazil: 11 years of experience at the Instituto de Oftalmologia de Manaus]. Rev Bras Oftalmol. 1996; 55(8): 619-22. Portuguese.

7. Amaral CS, Duarte JY, Silva PL, Valbuena R, Cunha F. [Indications for penetrating keratoplasty in Pernambuco]. Arq Bras Oftalmol. 2005;68(5):635-37. Portuguese.

8. Araujo AA, Melo GB, Silva RL, Araujo Neta VM. [Epidemiological profile of the patients on the waiting list for cornea transplantation in the State of Sergipe, Brazil]. Arq Bras Oftalmol. 2004;67(4):613-6. Portuguese.

9. Santhiago MR, Monica LA, Kara-Junior N, Gomes BA, Bertino PM, Mazurek MG, et al. [Profile of patient with aphakic/ pseudopfakic bullous keratopaty attended at public hospital]. Rev Bras Oftalmol. 2009;68(4):201-5. Portuguese.

\section{Corresponding author:}

Luiz Carlos Aguiar Vaz

Department of Pathology, FCM-UERJ - Ed. A. Piquet Carneiro

Rua Professor Manoel de Abreu, 444, Vila Isabel, Rio de Janeiro

/ RJ, Brazil CEP: 20550-170

Telephone: +55 21 2587-6380

E-mail: secretaria.anatpat@hotmail.com 